\title{
An original unified approach for the description of phase transformations in steel during cooling: first application to binary $\mathrm{Fe}-\mathrm{C}$
}

\author{
Olivier Bouaziz
}

Laboratoire d'Étude des Microstructures et de Mécanique des Matériaux (LEM3), CNRS, Université de Lorraine, Arts et Métier Paris Tech, F 57000, Metz, France

Received: 7 September 2018 / Accepted: 9 August 2019

\begin{abstract}
Exploiting Landau's theory of phase transformations, defining an original order parameter and using the phenomenological transformation temperatures, it is reported that it is possible to describe in a global approach the conditions for the formation of each constituent (ferrite, bainite, martensite) from austenite during cooling in steel. It allowed to propose a new rigorous classification of the different thermodynamic conditions controlling each phase transformation. In a second step, the approach predicts naturally the effect of cooling rate on the bainite start temperature. Finally, perspectives are assessed to extend the approach in order to take into account the effect of an external field such as applied stress.
\end{abstract}

Keywords: phase transformation / steel / austenite / ferrite / bainite / martensite / Landau / order parameter

\section{Introduction}

In the field of solid-state phase transformation in metallic alloys [1], the transformation of austenite in steel on cooling can occur by a variety of mechanisms including the formation of ferrite, bainite and martensite. The bainitic transformation occurs in a range between purely diffusional transformation to ferrite or pearlite and low temperature transformation to martensite by a displacive mechanism. Thus, the bainite transformation exhibits features of both diffusional and displacive transformations and has given rise to a large amount of research activity (see [2,3] for reviews). A major part of the research has concerned modelling of the kinetics of the transformations by detailed descriptions of the thermodynamic conditions operating at the interface [4-7]. However, the crucial understanding of the physically based conditions of the start of each phase transformation is less understood, especially for bainite.

Usually the $\mathrm{Ar}_{3}$ temperature is defined as the maximum temperature for any phase transformation of austenite to ferrite during cooling [8]:

$$
\begin{aligned}
\operatorname{Ar}_{3}\left({ }^{\circ} \mathrm{C}\right)= & 910-230 \mathrm{C}-21 \mathrm{Mn}-15 \mathrm{Ni} \\
& +45 \mathrm{Si}+32 \mathrm{Mo} .
\end{aligned}
$$

\footnotetext{
* e-mail: olivier.bouaziz@univ-lorraine.fr
}

For temperature lower than $\mathrm{Ar}_{3}$, the basical tools of physical metallurgy are the definition of the martensite start temperature $\mathrm{M}_{\mathrm{s}}$ and the bainite start temperature $\mathrm{B}_{\mathrm{s}}$ expressed phenomenologically as functions of chemical composition as:

$$
\begin{aligned}
\mathrm{M}_{\mathrm{S}}\left({ }^{\circ} \mathrm{C}\right)= & 539-423 \mathrm{C}-30.4 \mathrm{Mn}-17.7 \mathrm{Ni} \\
& -12.1 . \mathrm{Cr}-11 \mathrm{Si},
\end{aligned}
$$

where alloying element are expressed in weight(\%) [9], and [10]:

$$
\begin{aligned}
\mathrm{B}_{\mathrm{s}}\left({ }^{\circ} \mathrm{C}\right)= & 870-270 \mathrm{C}-90 \mathrm{Mn}-37 \mathrm{Ni} \\
& -70 \mathrm{Cr}-83 \mathrm{Mo} .
\end{aligned}
$$

In addition, another characteristic temperature is defined as the temperature where austenite and ferrite has the same thermo-chemical free energy determined as $[2,11]$ :

$$
\begin{aligned}
T_{0}\left({ }^{\circ} \mathrm{C}\right)= & 835-198 . \mathrm{C}-91 \mathrm{Mn}-36 \mathrm{Ni} \\
& -73 \mathrm{Cr}-15 \mathrm{Si}-87 \mathrm{Mo} .
\end{aligned}
$$

In this publication, it is showed that it is possible to describe in a global approach the conditions for each phase transformation exploiting completely Landau's theory 
[12-15] of phase transformations including an original order parameter and to propose a new classification of the different phase transformation in steel during cooling and to predict naturally the effect of cooling rate on bainite start temperature.

\section{The proposed approach}

In the framework of Landau's theory [12-14], for a second order phase transition, the free energy is expressed as:

$$
F(\chi, T)=F_{0}(T)+A(T) \cdot \chi^{2}+\mathrm{C} \cdot \chi^{4},
$$

where $T$ is the temperature, $\chi$ the order parameter, $F_{0}(T)$ the thermo-chemical free energy, $A(T)$ a function of temperature and $\mathrm{C}$ a positive constant.

The simplest expression for $A(T)$ is:

$$
A(T)=\mathrm{A}_{0}\left(T-T_{c}\right),
$$

with $\mathrm{A}_{0}$ a positive constant and $T_{c}$ a critical temperature where $A(T)$ changes of sign.

Usually in phase transformation of steels, $F_{0}(T)$ is known $[2,3,7]$. So, the identification of the total free energy $F(\chi, T)$ requires the determination of three parameters: $\mathrm{A}_{0}$, $T_{c}, \mathrm{C}$. of $\chi$ :

For $T>T_{c}, F(\chi, T)$ exhibits one minimum as a function

$$
\frac{\partial F(\chi, T)}{\partial \chi}=0
$$

for $\chi=0$ of $\chi$ :

For $T \leq T_{c}, F(\chi, T)$ exhibits two minima as a function

$$
\frac{\partial F(\chi, T)}{\partial \chi}=0
$$

for

$$
\chi= \pm \sqrt{\frac{\mathrm{A}_{0}\left(T_{c}-T\right)}{2 . \mathrm{C}}} .
$$

In order to exploit this approach to a classification of phase transformations in steel, it is now assumed that:

$$
T_{c}=\mathrm{B}_{\mathrm{s}},
$$

where $B_{s}$ is the bainite start temperature.

By convention, it is chosen to have an order parameter for martensite:

$$
\chi=\sqrt{\frac{\mathrm{A}_{0}\left(\mathrm{~B}_{\mathrm{s}}-\mathrm{M}_{\mathrm{s}}\right)}{2 \cdot \mathrm{C}}}=1 .
$$

Giving a first relationship:

$$
\frac{\mathrm{A}_{0}}{2 . \mathrm{C}}=\frac{1}{\mathrm{~B}_{\mathrm{s}}-\mathrm{M}_{\mathrm{s}}} .
$$

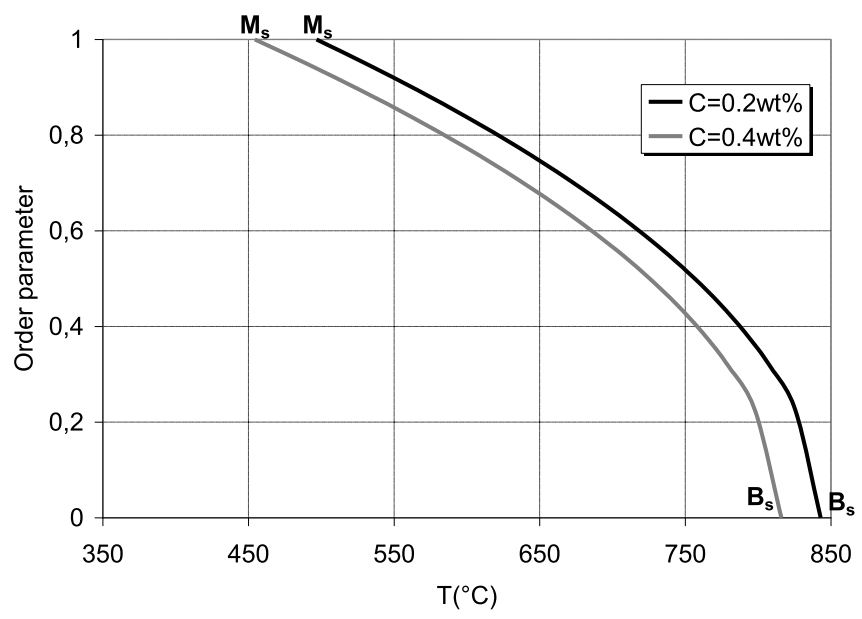

Fig. 1. Evolution of the order parameter from $B_{s}$ to $M_{s}$ temperatures for two different $\mathrm{Fe}-\mathrm{C}$ compositions.

Therefore, the order parameter is:

$$
\chi=\sqrt{\frac{\mathrm{B}_{\mathrm{s}}-T}{\mathrm{~B}_{\mathrm{s}}-\mathrm{M}_{\mathrm{s}}}} .
$$

As $B_{s}$ to $M_{s}$ temperatures depends on the carbon content, this one controls the order parameter.

In order to illustrate quantitatively this law, the evolution of the order parameter from $B_{s}$ to $M_{s}$ temperatures for two different $\mathrm{Fe}-\mathrm{C}$ compositions has been plotted in Figure 1.

It is now proposed to define clearly what could be the parameter of order for phase transformation in steels. If Cf is the carbon content of the phase appearing, it is reasonable to propose that:

$$
\chi=\frac{\mathrm{C}-\mathrm{C}_{\alpha, \mathrm{eq}}}{\mathrm{C}_{\gamma}-\mathrm{C}_{\alpha, \mathrm{eq}}},
$$

Where $\mathrm{C}_{\alpha \text {,eq }}$ is the solubility of carbon in ferrite at equilibrium and $\mathrm{C}_{\gamma}$ is the carbon in austenite. So, the order parameter can be a sursaturation in carbon in the binary $\mathrm{Fe}-\mathrm{C}$ system.

In addition, chemical free energy at $M_{s}$ has been determined as [14]:

$$
F_{0}\left(\mathrm{M}_{\mathrm{s}}, T\right)=F_{0}\left(\mathrm{M}_{\mathrm{s}}\right)+S_{0} \cdot\left(T-\mathrm{M}_{\mathrm{s}}\right),
$$

with $F_{0}\left(\mathrm{M}_{\mathrm{s}}\right)=1250 \mathrm{~J} / \mathrm{mol}$ and $S_{0}=-6.8 \mathrm{~J} \cdot \mathrm{mol}^{-1} \cdot \mathrm{K}^{-1}$, which are independent of the composition.

The energy value $F_{0}\left(\mathrm{M}_{\mathrm{s}}\right)$ should correspond to the maximum at $\mathrm{M}_{\mathrm{s}}$ for $\chi=0$. As for any $T<\mathrm{B}_{\mathrm{s}}$ this maximum exists for the same value of $\chi=0$, it is written for $\mathrm{M}_{\mathrm{s}} \leq T<\mathrm{B}_{\mathrm{s}}$ :

$$
F(0, T)=F_{0}\left(T-\mathrm{M}_{\mathrm{s}}\right)+F_{0}\left(\mathrm{M}_{\mathrm{s}}\right),
$$

with

$$
F_{0}\left(T-\mathrm{M}_{\mathrm{s}}\right)=S_{0} \cdot\left(T-\mathrm{M}_{\mathrm{s}}\right),
$$




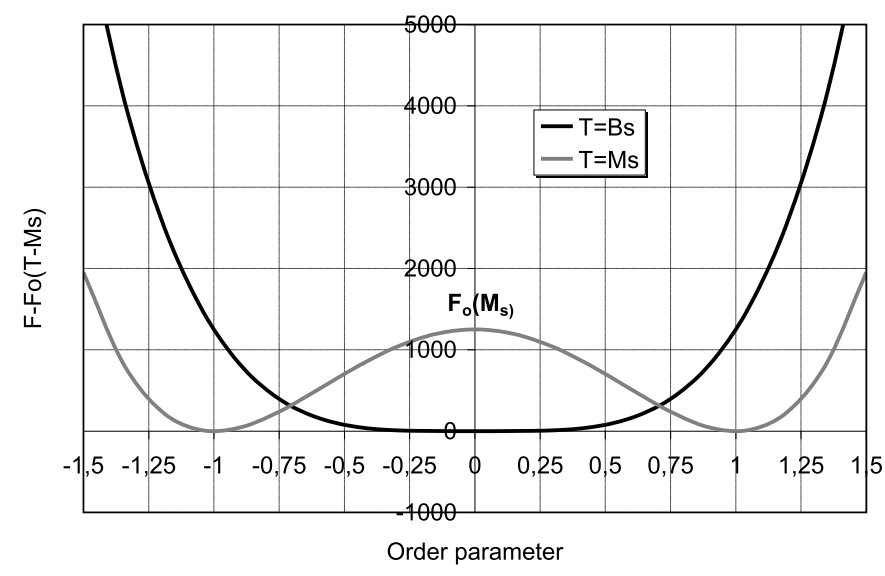

Fig. 2. Evolution of the $F(\chi, T)-F_{0}\left(T-\mathrm{M}_{\mathrm{s}}\right)$ as a function of the order parameter at $\mathrm{B}_{\mathrm{s}}$ and at $\mathrm{M}_{\mathrm{s}}$ temperatures.

when $T$ is near $\mathrm{M}_{\mathrm{s}}$ but it can be completely different for higher temperature.

In order to determine $\mathrm{A}_{0}$ and $\mathrm{C}$, as the total free energy at $M_{\mathrm{s}}$ for $\chi=1$ has to be zero, it comes:

$$
F_{0}\left(\mathrm{M}_{\mathrm{s}}\right)+\mathrm{A}_{0}\left(\mathrm{M}_{\mathrm{s}}-\mathrm{B}_{\mathrm{s}}\right)+\mathrm{C}=0,
$$

or

$$
\mathrm{C}=2 \mathrm{C}-F_{0}\left(\mathrm{M}_{\mathrm{s}}\right)
$$

and

$$
\mathrm{C}=F_{0}\left(\mathrm{M}_{\mathrm{s}}\right)
$$

Consequently:

$$
\mathrm{A}_{0}=\frac{2 \cdot F_{0}\left(\mathrm{M}_{\mathrm{s}}\right)}{\mathrm{B}_{\mathrm{s}}-\mathrm{M}_{\mathrm{s}}}
$$

Finally it is possible to express completely the free energy:

$$
\begin{aligned}
F(\chi, T) & =F_{0}\left(T-\mathrm{M}_{\mathrm{s}}\right)+F_{0}\left(\mathrm{M}_{\mathrm{s}}\right) \\
& +\frac{2 \cdot F_{0}\left(\mathrm{M}_{\mathrm{s}}\right)}{\mathrm{B}_{\mathrm{s}}-\mathrm{M}_{\mathrm{s}}}\left(T-\mathrm{B}_{\mathrm{s}}\right) \cdot \chi^{2}+F_{0}\left(\mathrm{M}_{\mathrm{s}}\right) \cdot \chi^{4},
\end{aligned}
$$

or

$$
\begin{aligned}
F(\chi, T) & =F_{0}\left(T-\mathrm{M}_{\mathrm{s}}\right)+F_{0}\left(\mathrm{M}_{\mathrm{s}}\right) \\
& +F_{0}\left(\mathrm{M}_{\mathrm{s}}\right) \cdot \chi^{2}\left(2 \cdot \frac{\left(T-\mathrm{B}_{\mathrm{s}}\right)}{\mathrm{B}_{\mathrm{s}}-\mathrm{M}_{\mathrm{s}}}+\chi^{2}\right) .
\end{aligned}
$$

\begin{tabular}{|c|c|c|}
\hline Phase & Free energy & Order parameter \\
\hline Ferrite & $\frac{\partial F(\chi, T)}{\partial \chi}=0$ & $\chi=0$ \\
\hline Bainite & $\begin{array}{l}\frac{\partial F\left(\chi, \mathrm{B}_{\mathrm{s}}\right)}{d \chi}=0 \\
\frac{\partial^{2} F\left(\chi, \mathrm{B}_{\mathrm{s}}\right)}{\partial \chi^{2}}=0\end{array}$ & $T<\mathrm{B}_{\mathrm{s}}, \chi=\sqrt{\frac{\mathrm{B}_{\mathrm{s}}-T}{\mathrm{~B}_{\mathrm{s}}-\mathrm{M}_{\mathrm{s}}}}$ \\
\hline Martensite & $\begin{array}{l}F\left(\chi, \mathrm{M}_{\mathrm{s}}\right)=0 \\
\frac{\partial F\left(\chi, \mathrm{M}_{\mathrm{s}}\right)}{\partial \chi}=0\end{array}$ & $\chi=1$ \\
\hline
\end{tabular}

In order to highlight the key role of the order parameter, it has been drawn in Figure 2. The evolution of the rightend side term of the expression:

$$
\begin{aligned}
F(\chi, T)-F_{0}\left(T-\mathrm{M}_{\mathrm{s}}\right) & =F_{0}\left(\mathrm{M}_{\mathrm{s}}\right) \\
& +F_{0}\left(\mathrm{M}_{\mathrm{s}}\right) \cdot \chi^{2}\left(2 \cdot \frac{\left(T-\mathrm{B}_{\mathrm{s}}\right)}{\mathrm{B}_{\mathrm{s}}-\mathrm{M}_{\mathrm{s}}}+\chi^{2}\right) .
\end{aligned}
$$

Table 1. Classification of phase transformation conditions from austenite during cooling.

Finally, the quantitative developed approach can be used in order to summarized the thermodynamic conditions for the formation of each phase, as it is summarized in Table 1, providing more rigorous occurrence criterion especially to distinguish ferrite, bainite or martensite formation.

\section{Extended approach including cooling rate}

It is well known that $B_{s}$ decreases if the cooling rate is increased. In order to capture this effect using the previous approach, it is assumed that a kinetic equation for the order parameter can be written for $T<\mathrm{B}_{\mathrm{s}}$ as:

$$
\frac{\partial \chi}{\partial t}=-\eta \cdot \frac{\partial F(\chi, T)}{\partial T}
$$

where $\eta$ is independent of $\chi$ and of $T$, giving for $T<\mathrm{B}_{\mathrm{s}}$ :

$$
\frac{\partial \chi}{\partial t}=\eta \cdot \mathrm{A}_{0} \cdot \chi^{2}
$$

Using equation (13), it is also possible to express:

$$
\frac{\partial \chi}{\partial T}=\frac{-\sqrt{\frac{1}{\mathrm{~B}_{\mathrm{s}}-\mathrm{M}_{\mathrm{s}}}}}{2 \cdot \sqrt{\mathrm{B}_{\mathrm{s}}-T}}=-\frac{1}{2 \cdot \sqrt{\left(\mathrm{B}_{\mathrm{s}}-T\right) \cdot\left(\mathrm{B}_{\mathrm{s}}-\mathrm{M}_{\mathrm{s}}\right)}} .
$$

Therefore:

$$
\frac{d T}{d t}=\frac{\partial x}{\partial t} / \frac{\partial x}{\partial T} .
$$


It comes using equations (26) and (28):

$$
\frac{\frac{d T}{d t}=-2 \cdot \eta \cdot \mathrm{A}_{0} \cdot\left(\mathrm{B}_{\mathrm{s}}-T\right)^{3 / 2}}{\sqrt{\mathrm{B}_{\mathrm{s}}-\mathrm{M}_{\mathrm{s}}} .}
$$

Combining with equation (21), we have:

$$
\frac{d T}{d t}=-2 \cdot \eta \cdot F_{0}\left(\mathrm{M}_{\mathrm{s}}\right) \cdot\left(\frac{\mathrm{B}_{\mathrm{s}}-T}{\mathrm{~B}_{\mathrm{s}}-\mathrm{M}_{\mathrm{s}}}\right)^{3 / 2} .
$$

Thus, the temperature $T$ respecting equation (32) is:

$$
T=\mathrm{B}_{\mathrm{s}}-\left(\mathrm{B}_{\mathrm{s}}-\mathrm{M}_{\mathrm{s}}\right) \cdot\left(\frac{-1}{2 \cdot \eta \cdot F_{0}\left(\mathrm{M}_{\mathrm{s}}\right)} \frac{d T}{d t}\right)^{2 / 3}
$$

with $\frac{d T}{d t} \leq 0$ during cooling. This temperature is the bainite start temperature affected by the cooling rate.

As $T \geq \mathrm{M}_{\mathrm{s}}$, equation (33) gives a critical cooling rate for $T=\mathrm{M}_{\mathrm{s}}$ :

$$
\frac{d T}{d t}=-2 \cdot \eta \cdot F_{0}\left(\mathrm{M}_{\mathrm{s}}\right)
$$

In addition, a formula has been determined for the critical cooling rate in order to form $1 \%$ of martensite from austenite [16]:

$$
\begin{aligned}
\log \left(-C_{r}\right) & =4.5-2.7 \mathrm{C}-0.95 \mathrm{Mn}-0.18 \mathrm{Si} \\
& -0.38 \mathrm{Cr}-1.29(\mathrm{C} . \mathrm{Cr})
\end{aligned}
$$

where $C_{r}$ is expressed in ${ }^{\circ} \mathrm{C} / \mathrm{s}$.

Moreover, using equation (34) and (35), it is consistent to impose that:

$$
2 . \eta \cdot F_{0}\left(\mathrm{M}_{\mathrm{s}}\right)=C_{r}
$$

and

$$
\eta=\frac{C_{r}}{2 \cdot F_{0}\left(\mathrm{M}_{\mathrm{s}}\right)}
$$

Finally, the law predicting the evolution of the bainite start temperature as a function of cooling rate is:

$$
T=\mathrm{B}_{\mathrm{s}}-\left(\mathrm{B}_{\mathrm{s}}-\mathrm{M}_{\mathrm{s}}\right) \cdot\left(\frac{-1}{C_{r}} \frac{d T}{d t}\right)^{2 / 3} .
$$

In order to illustrate quantitatively this law, the evolution of the bainite start temperature as a function of cooling rate for two different $\mathrm{Fe}-\mathrm{C}$ compositions has been plotted in Figure 3.

\section{Conclusions}

Exploiting Landau's theory of phase transformations, defining an original order parameter and using the phenomenological transformation temperatures, it is reported that it is possible to describe in a global approach the conditions for the formation of each phase (ferrite,

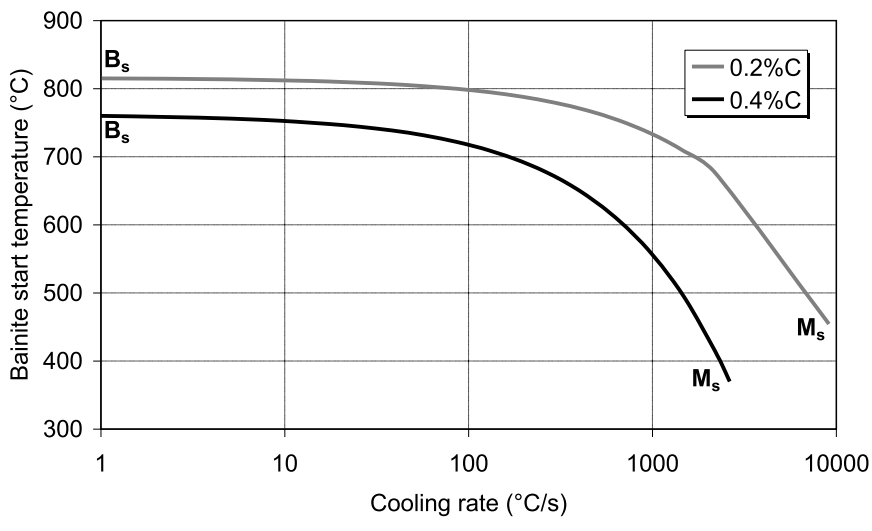

Fig. 3. Evolution of the bainite start temperature as a function of cooling rate for two different $\mathrm{Fe}-\mathrm{C}$ compositions.

bainite, martensite) from austenite during cooling in steel. It allowed to propose a new rigorous classification of the different thermodynamic conditions controlling each phase transformation. In a second step, the approach predicts naturally the effect of cooling rate on the bainite start temperature. In perspectives, the approach can be extended to take into account external fields by adding a linear term in free energy linearly proportional to the order of parameter and proportional to the potential energy of the external field [12-14]. For instance, in the case of an uniaxial applied stress $\sigma$, the contribution to the free energy is expressed as:

$$
F(\chi, \sigma))= \pm \frac{\sigma^{2}}{2 . E} \cdot \chi
$$

where $E$ is the elastic modulus and the sign depends on the compressive or tensile stress.

This term breaks the symmetry of the total free energy as a function of the parameter of order and it can change the occurrence conditions of each phase. A lot of experimental data are available is the literature in order to validate this last point which will be investigated in a next future.

Acknowledgement. The author thanks Dr. F. Levy for stimulating discussions.

\section{References}

1. M. Hillert, Phase equilibria, Phase diagrams and Phase tranformations, 2nd ed., Cambridge University Press, Cambridge, UK, 2008

2. H.K.D.H. Bhadeshia, Bainiet in steels, 2nd ed., IOM Communication Ltd., London, 2001

3. M. Hillert, Paraequilibrium and other restricted equilibria, in: L.H. Bennet, T.B. Massalski, B.C. Giessen (Eds), Alloy phase diagrams, Mater. Res. Soc. Symp. Proc. 19, 295 (1983).

4. J.S. Kirkaldy, Can. J. Phys. 36, 907 (1958)

5. A. Hultgren, Trans. ASM. 39, 915 (1947)

6. M. Takahashi, Curr. Opin. Solid State Mater. Sci. 8, 213 (2004) 
7. H.S. Zurob, C.R. Hutchinson, Y. Bréchet, H. Seyedrezai, G. Purdy, Acta Mater. 57, 2781 (2009)

8. F.B. Pickering, Steels: Metallurgical principles, in: Encyclopedia of Materials Science and Engineering, Vol. 6, The MIT Press, Cambridge, 1986

9. K.W. Andrews, J. Iron Steel Inst. 203, 721 (1965)

10. W. Steven, A.G. Haynes, JISI. 183, 349 (1956)
11. S.M.C. Van Bohemen, Metall. Trans. A 41, 285 (2010)

12. L.D. Landau, E.M. Lipschitz, Statistical Physics, Pergamon, London, 1959

13. R.A. Cowley, Adv. Phys. 29, 1 (1980)

14. F. Falk, J. Phys. Colloq. 43, C-4-3 (1982)

15. J. Wang, S. Van der Zwaag, Metall. Trans. A 32, 1527 (2001)

16. A. Moulin, ArcelorMittal Research, Internal Report, 2001

Cite this article as: Olivier Bouaziz, An original unified approach for the description of phase transformations in steel during cooling: first application to binary Fe-C, Metall. Res. Technol. 116, 615 (2019) 